\title{
Inverter Control Strategy for PMSG Based WECS with Battery for a Standalone System
}

\author{
${ }^{* 1}$ Shashikant, ${ }^{2}$ Binod Shaw, ${ }^{3}$ Bindu Naidu \\ ${ }^{1,2,3}$ National Institute of Technology, Raipur -492010 , India \\ Email: shashikantkaushaley20@gmail.com,binodshaw2000@gmail.com,bindunaidu.1990@gmail.com
}

Received: 06th October 2019, Accepted: 31st January 2020, Published: 29th February 2020

\begin{abstract}
In a standalone wind energy conversion system, variation in load affects the power quality (voltage and frequency at PCC) due to the presence of power electronic devices which introduces harmonics in the system. Moreover, wind speed variation is also one of the reason for voltage fluctuation. In this paper the proposed inverter control strategy is able to mitigate the harmonics in the system and improves the power quality. The proposed system contains a battery with a controller which helps the system to integrate it with other renewable energy system such as solar PV system, Fuel cell system, etc. The system is modelled in MATLAB Simulink and the simulation results supports the system for further integration with other renewable energy system.
\end{abstract}

\section{Keywords}

WECS, PMSG, Inverter Control, Bi-Directional DC-DC Converter Control, Battery.

\section{Introduction}

Permanent Magnet Synchronous Generator (PMSG) based Wind Energy Conversion System (WECS) is of great interest to the researcher nowadays because of its advantages. The advantages of PMSG are; 1) it doesn't requires extra dc supply for excitation, dc excitation is provided via permanent magnets hence no copper losses in excitation system, 2) Absence of commutator, brushes and slip rings which makes no mechanical losses, 3) Compactness. Earlier Doubly Fed Induction Generators (DFIG) are used in wind farms. A comparative analysis on power quality of DFIG based WECS and PMSG based WECS. PMSG has better performance over DFIG over conventional power electronic devices [1]. The PMSG model used in this paper for study is taken from [2]. The performance of PMSG based mathematical model is improved via different MPPT technique, [3] have used optimal torque control which is implemented in this paper for improving the quality of study and performance. [4] Illustrated different MPPT technique and [5] have implemented using microcontroller, all these MPPT have supported this paper to carry out the research. Calculation of power generated from wind turbine at constant wind speed is illustrated in [6]. Further support of PMSG model with integrated with other renewable energy sources is implemented via [7] and a review paper by [8]. [9] Have discussed the future of Hybrid system based on renewable system with PMSG. Finally the design of robust PMSG is illustrated in [10].

Following the paper are structured as system investigation followed by proposed inverter control strategy followed by proposed DC-DC bidirectional converter thereafter followed by result and discussions, conclusion and finally the references.

\section{System Investigated}

Dynamic behaviour of Permanent Magnet Synchronous Generator based Wind Energy Conversion System is analysed in this paper. The whole system consists of wind turbine, PMSG, filter, diode rectifier, chopper, three phase inverter, battery and a load. The block diagram of whole system is shown in Fig 1. Equation 1-3 is used to model the wind turbine and equation 4-6 represents the modelling of generator in d-q coordinate system.

$\mathrm{P}_{\mathrm{m}}=0.5 \rho \mathrm{C}_{\mathrm{p}} \mathrm{AV}^{3}=0.5 \rho \mathrm{C}_{\mathrm{p}} \mathrm{A}\left(\frac{\omega_{m} R}{\lambda}\right)^{2}$

$\mathrm{T}_{\mathrm{m}}=\frac{1}{2 \lambda} \rho \pi \mathrm{R}^{3} \mathrm{~V}^{2} \mathrm{C}_{\mathrm{p}}(\lambda)$

$\lambda=\frac{\omega_{m} R}{V}$

Where, $\mathrm{Pm}$ and Tm represents the power and torque developed by the wind turbine, $\lambda$ is the tip speed ratio. $\rho$ is the air density in $\mathrm{Kg} / \mathrm{m}^{3}$, A is the area swept by the blade in $\mathrm{m}^{2}, \mathrm{~V}$ is the wind velocity in $\mathrm{m} / \mathrm{s}, \mathrm{C}_{\mathrm{p}}$ is the power coefficient of the turbine, $\omega_{\mathrm{m}}$ is the angular speed of the generator in $\mathrm{rad} / \mathrm{sec}, \mathrm{R}$ is the radius of the wind turbine blade.

$V_{q}=-\left(R+\mathrm{p} L_{q}\right) i_{q}-\omega_{r} L_{d} i_{d}+\omega_{r} \lambda_{m}$

$V_{d}=-\left(R+\mathrm{p} L_{d}\right) i_{d}-\omega_{r} L_{q} i_{q}$

$T_{e}=\frac{3}{2}\left(\frac{P}{2}\right)\left[\left(L_{d}-L_{q}\right) i_{d} i_{q}-\lambda_{m} i_{q}\right]$ 
Where, $\mathrm{L}$ and $\mathrm{R}$ are the machine inductance and resistance in per phase, $\mathrm{i}_{\mathrm{d}}, \mathrm{i}_{\mathrm{q}}, \mathrm{V}_{\mathrm{d}}$ and $\mathrm{V}_{\mathrm{q}}$ are the two-axis machine currents and voltages, $p$ represents the differentiation with respect to time, $\lambda_{m}$ is the amplitude of flux linkages established by the permanent magnet. $T_{e}$ is the electromagnetic torque of the generator in which $P$ represents the number of poles. The next stage after generator is the diode rectifier circuit and its output voltage and current is represented in equation 7 and 8 . The output voltage of the diode rectifier circuit varies with respect to the variation in wind. The output voltage and current contains harmonics due to diode and hence a LC filter is introduced to filter out the harmonic component and its value is obtained from equation 9 and 10.

$V_{d c}=\frac{3 V_{m}}{\pi}$

$I_{d c}=\frac{V_{d c}}{\pi}$

$C_{i n}=\frac{(5 \sim 10 \%) P_{\text {in }}}{2 \pi f_{i n} V^{2}{ }_{i n, l-l, r m s}}$

$L_{\text {in }}=\frac{1}{\left(2 \pi f_{c}\right)^{2} C_{\text {in }}} \approx \frac{1}{\left(2 \pi 0.1 f_{s}\right)^{2} C_{\text {in }}}$

Two channel interleaved Boost converter (IBC) is proposed in this paper, which shares a single output filter capacitor for both the parallel paths. IBC the equivalent switching frequency of the converter is increased due to which the ripples in the input current and output voltage are reduced and hence the overall system dynamic response is improved as illustrated in [11]. The input current ripple of two channel IBC is represented in equation 11. The duty cycle of this converter is given such that it tracks maximum power from WECS. In order to track maximum power Perturb and Observe method is used. This stage makes the system stable irrespective of the variation in wind velocity. . The next stage is the inverter section which converts de quantity in to ac quantity. The ac quantity of the inverter is measured by equation 12 .

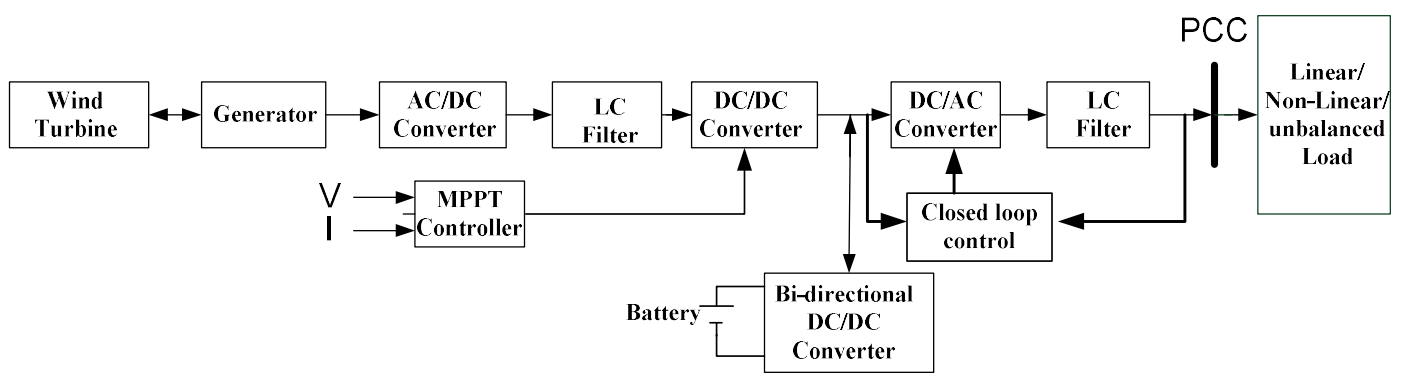

Fig 1: Block Diagram of the Proposed Standalone WECS.

$\Delta I_{i}=(1-2 D) D \frac{V_{o} T_{S}}{L} ; \quad 0<D \leq 0.5$

$\Delta I_{i}=(2 D-1)(1-D) D \frac{V_{o} T_{S}}{L} ; 0.5<D \leq 1$

$\mathrm{V}_{\mathrm{L}}=\frac{\sqrt{3}}{2 \sqrt{2}} \mathrm{mV}_{\mathrm{dc}}$

Where, D represents the duty ratio, $\mathrm{L}$ is the inductor of the two channel IBC $\left(L=L_{1}=L_{2}\right), V_{o}$ is the output voltage and $T_{S}$ is the switching period. $\mathrm{V}_{\mathrm{L}}$ is the rms line to line voltage on ac side where load is connected, $\mathrm{V}_{\mathrm{dc}}$ is the $\mathrm{dc}$ link voltage or the input of the inverter section, and $\mathrm{m}$ is the modulation index. A battery is used with bidirectional DC-DC converter to support the standalone system.

Inverter Control Methodology

The objective of this proposed control methodology shown in Fig 2 serves for two purpose:

(i) To maintain the DC link voltage constant irrespective of fluctuation in wind.

(ii) To reduce the voltage fluctuation at PCC for different load change condition. 


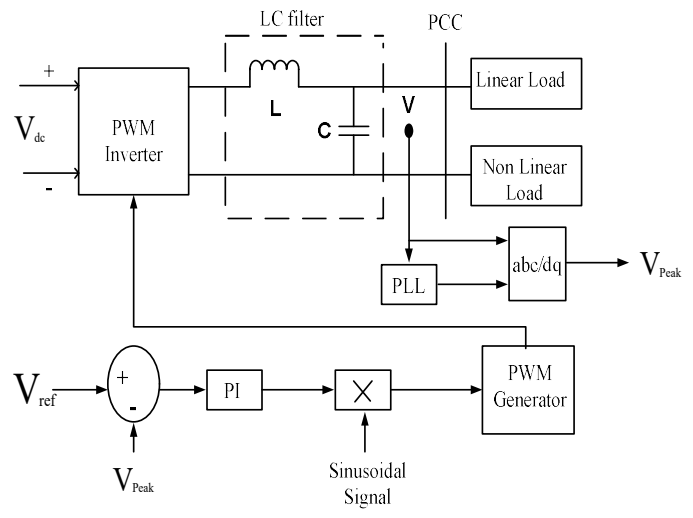

Fig 2: Block Diagram of Proposed Inverter Controller.

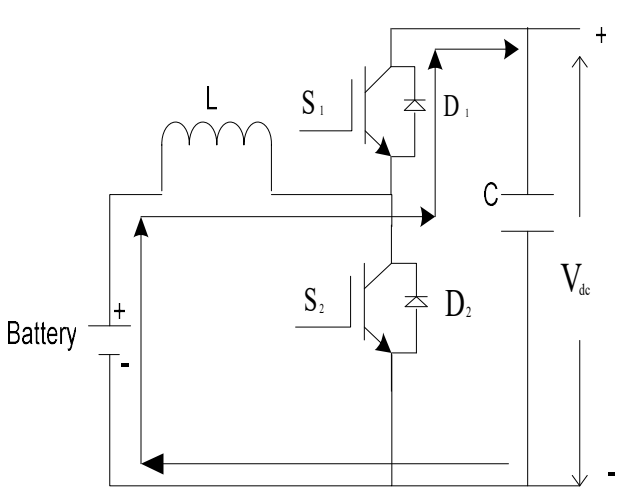

Fig 3: Bidirectional DC-DC Converter.

In the proposed controller the voltage at PCC is sensed and passed to phase locked loop (PLL). The angular frequency generated by PLL along with voltage at PCC is then feed to abc/dq transformation block. The dq represents the DC values of the system and it represents the peak value of AC voltage at PCC. A sudden change in load causes voltage fluctuation at PCC. The motive of this controller is to maintain the voltage of PCC near reference voltage. The peak value of voltage detected by the abc/dq transformation block is compared with reference peak value of voltage and an error between them is feed to PI controller. The PI controller minimises the error between the two voltages. The output of PI controller is multiplied with a sinusoidal signal and this sinusoidal signal is feed to PWM generator which generates gating pulses for the inverter. Hence the amplitude of the voltage waveform is controlled in a closed loop and its value is maintained at the reference value by the controller.

\section{Proposed DC-DC Bidirectional Converter}

In order to maintain the DC link voltage constant the charging and discharging of the battery should be properly controlled and this motive is attained by designing a proper control system which act as a battery controller. The bidirectional DC-DC converter is shown in Fig 3 and the control strategy is shown in Fig 4. The controller controls the turn on and turn off time of switches $\mathrm{S}_{1}$ and $\mathrm{S}_{2}$ of the bi-directional DC-DC converter.

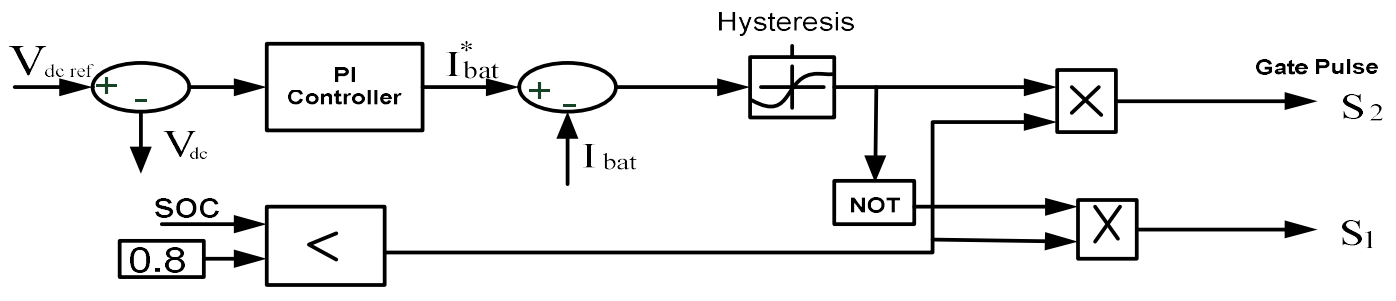

Fig 4: Controller for Bi-directional DC-DC Converter.

The operational modes of bi-directional DC-DC converter controller are explained as follows:

(a) Mode 1: The error between the reference DC voltage and DC link voltage is sensed by the PI controller and when the measured DC voltage is greater than the reference DC voltage the bi-directional DC-DC converter acts as buck converter and charges the battery by controlling the charging current until the State of charge (SOC) of battery is not greater than 0.8 .

(b) Mode 2: When the SOC of battery is greater 0.8 and the measured DC voltage is greater than reference DC voltage the battery stops charging and the excess power is stored in the DC link.

(c) Mode 3: When the measured DC voltage is less than the reference DC voltage and the SOC of battery is greater than 0.8 , the battery starts discharging through the bi-directional DC-DC converter in order to maintain the DC link voltage constant.

\section{Result and Discussions}

The proposed model is modelled and simulated in MATLAB Simulink. Paper objective is to maintain voltage at PCC bus constant irrespective of change in load and irrespective of change in wind speed. Hence, model is simulated under dynamic condition in which at time $\mathrm{t}=0.5 \mathrm{sec}$ wind speed decreases from $12 \mathrm{~m} / \mathrm{s}$ to $8 \mathrm{~m} / \mathrm{s}$ and at the same time load is increased from $3.8 \mathrm{KW}$ to $6 \mathrm{KW}$ as shown in Fig 5(a) and (b), the system performance is designed for $12 \mathrm{~m} / \mathrm{s}$ wind speed as reference speed. Hence, the system is operated under different loading conditions and also operated at different modes i.e. at different wind speed. If the system is operated under different modes i.e. at higher rated speed $(>12 \mathrm{~m} / \mathrm{s})$ and under rated speed $(<12 \mathrm{~m} / \mathrm{s})$, its performance varies i.e. 
generated power gets increased or decreased when operated in higher rated speed or lower rated speed which may leads to instability. In order to maintain stability, controller is provided to make system stable. In this work, the system is initially operated at rated condition and thereafter operated as under rated condition i.e. low wind speed. At this condition the instantaneous value of voltage and rms value of voltage at Point of Common Coupling (PCC) without controller is shown in Fig 5 (c) and (d), and with controller it is shown in Fig 5 (e) and (f). From Fig 5 (c) and $(\mathrm{d})$ it is observed that the voltage gets reduced at PCC due to increase in load and also with decrease in wind speed. From Fig 5 (e) and (f) it is observed that the voltage remains constant irrespective of change in load and variation in wind speed due to controller present in the system and hence, voltage stability is which enhances system stability.

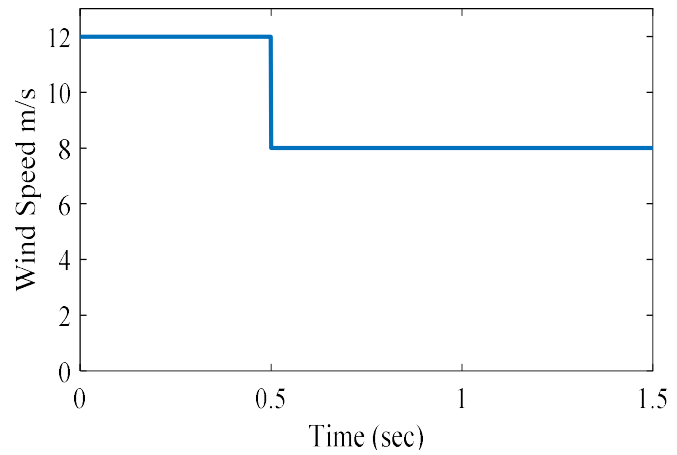

(a)

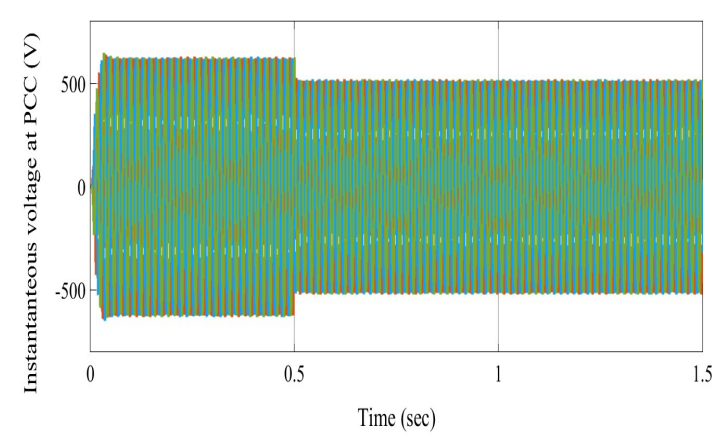

(c)

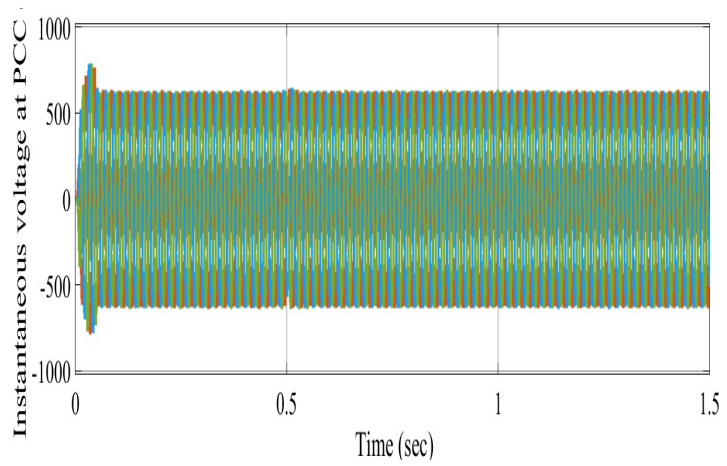

(e)

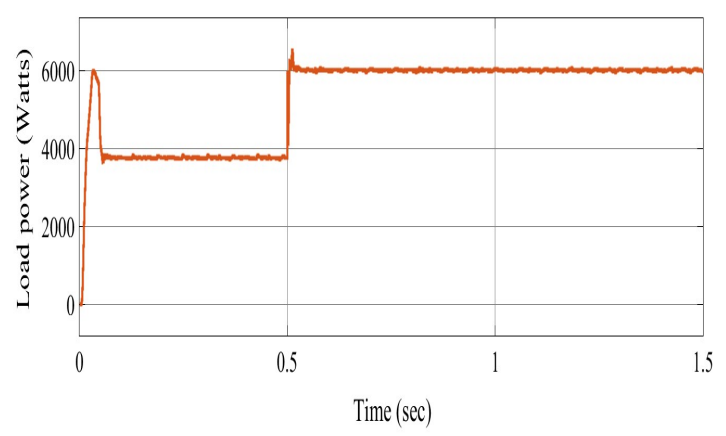

(b)

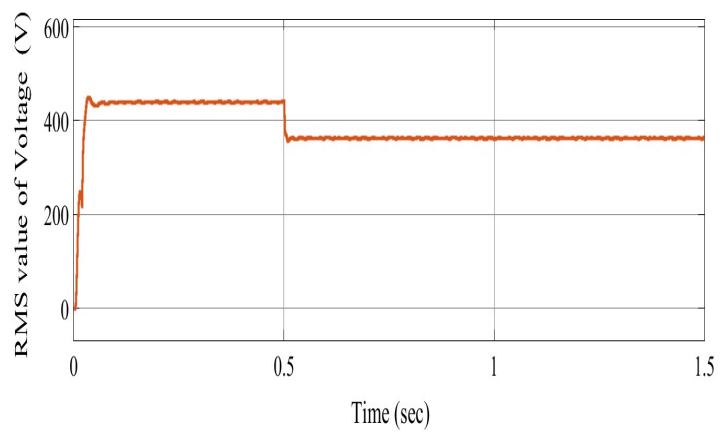

(d)

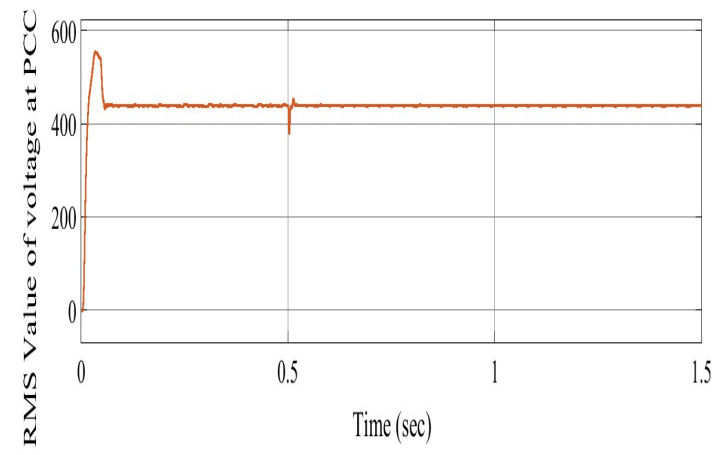

(f)

Fig 5. (a) Waveform of Wind Speed. (b) Waveform of Load Profile, (c) Represents Instantaneous Value of Voltage Without Controller, (d) Represents RMS Value of Voltage Without Controller (e) Represents Instantaneous Value of Voltage With Controller and (f) Represents RMS Value of Voltage With Controller. 


\section{Conclusion}

In this paper, a standalone PMSG based wind energy conversion system has been analysed for different wind speed and different loading condition. An efficient control has been proposed in order to keep the voltage at PCC near a reference value in order to fulfil the requirements as well as the DC link voltage is maintained constant with proper modes of control of DC-DC bidirectional converter which enables proper charging and discharging of a battery, with this method it is concluded that other renewable energy sources can be integrated with this system. This research work is related to seed grant project under the supervision of Dr. Binod Shaw.

\section{References}

1. L. Gidwani, "A comparative power quality study of DFIG and PMSG based wind energy conversion system," WSEAS Trans. Syst. Control, vol. 10, pp. 38-47, 2015.

2. M. Rahimi, "Mathematical modeling, dynamic response analysis , and control of PMSG - based wind turbines operating with an alternative control structure in power control mode," no. July, pp. 1-18, 2017.

3. Z. R. Labidi, H. Schulte, and A. Mami, "Modeling and Optimal Torque Control of Small Wind Turbines with Permanent Magnet Synchronous Generators," 2017.

4. M. Nasiri, J. Milimonfared, and S. H. Fathi, "Modeling, analysis and comparison of TSR and OTC methods for MPPT and power smoothing in permanent magnet synchronous generator-based wind turbines," Energy Convers. Manag., vol. 86, pp. 892-900, 2014.

5. B. Lahfaoui, S. Zouggar, B. Mohammed, and M. Larbi, "Real time study of P \& O MPPT control for small wind PMSG turbine systems using Arduino microcontroller," Energy Procedia, vol. 111, no. September 2016, pp. 1000-1009, 2017.

6. B. Ioan, B. Horia, O. Pop, and T. Susana, "Determination of the Power Generated by a Wind Turbine in Constant Wind and Variable Wind," pp. 769-773, 2015.

7. D. Akinyele, "Battery Storage Technologies for Electrical Applications : Impact in Stand-Alone Photovoltaic Systems," pp. 1-39.

8. Z. Alnasir and M. Kazerani, "An analytical literature review of stand-alone wind energy conversion systems from generator viewpoint,” Renew. Sustain. Energy Rev., vol. 28, pp. 597-615, 2013.

9. P. Nema, R. K. Nema, and S. Rangnekar, "A current and future state of art development of hybrid energy system using wind and PV-solar: A review," vol. 13, pp. 2096-2103, 2009.

10. S. Zhang et al., "Design of a Robust Grid Interface System for PMSG-Based Wind Turbine Generators," IEEE Trans. Ind. Electron., vol. 58, no. 1, pp. 316-328, 2011.

11. A. Thiyagarajan, "Analysis and Comparison of Conventional and Interleaved DC / DC boost converter," Second Int. Conf. Curr. Trends Eng. Technol. - ICCTET 2014, pp. 198-205, 2014. 